\title{
Keamanan Pesan Rahasia Menggunakan Steganografi DCT (Discrete Cosine Transform) pada Citra JPEG
}

\author{
Dian Hafidh Zulfikar ${ }^{1)}$ \\ ${ }^{1)}$ Program Studi Sistem Informasi, Universitas Islam Negeri Raden Fatah Palembang \\ Jl. Prof. K.H. Zainal Abidin Fikry KM 3.5 Palembang 30126 \\ Email : dianhafidhzulfikar_uin@radenfatah.ac.id ${ }^{1)}$
}

\begin{abstract}
The least significant-bit (LSB) based techniques are very popular for steganography in spatial domain. The simplest LSB technique simply replaces the LSB in the cover image with the bits from secret information. Further advanced techniques use some criteria to identify the pixels in which $L S B(s)$ can be replaced with the bits of secret information. In Discrete Cosine Transform (DCT) based technique insertion of secret information in carrier depends on the DCT coefficients. Any DCT coefficient value above proper threshold is a potential place for insertion of secret information.
\end{abstract}

Keywords : Discrete Cosine Transform (DCT), steganography, secret message

\section{Abstrak}

Pada steganografi domain spasial, teknik least significant-bit (LSB) merupakan teknik yang paling banyak digunakan pada steganografi. Teknik yang sederhana yang hanya mengubah nilai LSB pada cover image dengan nilai bit pesan rahasia, atau dengan teknik yang lebih baik lagi yaitu dengan menentukan bit-bit LSB mana yang akan dilakukan pergantian nilai bit. Lain halnya dengan metode Discrete Cosine Transform (DCT), teknik steganografi ini akan menyembunyikan informasi rahasia tergantung dari nilai Koefisien DCT.

Kata Kunci : Steganografi, DCT, Citra, JPEG, Pesan Rahasia 


\section{Pendahuluan}

Upaya penyembunyian informasi (message) tidak hanya dapat dilakukan dengan mengubah pesan tersebut menjadi pesan yang tidak bisa dipahami, tapi dapat dilakukan juga dengan menyisipkan pesan tersebut ke dalam media lain (Morkel dkk,2005). Sehingga orang tidak akan curiga terhadap pesan yang dikirimkan, karena pesan tersebut tidak terlihat. Yang terlihat hanyalah media penampung pesan tersebut. Teknik penyisipan pesan dalam media lain ini dinamakan Steganografi (Roy dkk, 2013).

Terdapat beberapa penelitian pada metode steganografi yang dalam teknik penyisipanya menggunakan transformasi Discrete Cosine Tranform DCT (Walia dkk, 2010), secara umum proses penyisipan pesan pada kawasan det dilakukan dengan menyisipkan pesan rahasia pada LSB diarea koefisien DCT hasil kuantisasi secara sekuensial (Reddy dkk, 2011). Berbeda pada kebanyakan proses steganografi pada kawasan dct, pada steganografi dct dengan metode F5 menggunakan metode baru dalam cara penggantian LSB pada koefisien DCT dengan data pesan, dimana F5 tidak mengganti koefisien DCT namun mengurangi bit koefisien DCT dengan data pesan (Fridrich dkk, 2002).

Konsep penyisipan pesan pada citra sebenarnya adalah proses mengganti nilai bit pesan dengan nilai pixel yang ada pada citra sedemikian sehingga pesan yang disisipkan mampu tersamarkan dalam nilai pixel citra, sehingga dapat memanipulasi keterbatasan visual manusia (Patel dan Dave, 2012), secara umum proses penyisipan pesan pada kawasan det dilakukan dengan menyisispkan pesan rahasia pada LSB diarea koefisien DCT hasil kuantisasi (Westfeld, 2001).

Penilaian sebuah algoritma steganografi yang baik dapat dinilai dari beberapa faktor salah satunya yaitu kualitas (fidelity) yaitu dimana mutu atau kualitas citra penampung setelah ditambahkan pesan tidak jauh berbeda dengan kualitas citra penampung sebelum ditambahkan pesan dan yang kedua adalah ketahanan (robustness) yaitu data yang disembunyikan harus tahan terhadap berbagai operasi manipulasi atau penambahan image distortion yang dilakukan pada citra stego (Murwantini, 2007).

Masalah yang timbul adalah apakah algoritma dct baik atau layak untuk digunakan dalam steganografi. Oleh karena itu selain akan dilakukan penerapan proses steganografi pada kawasan dct juga akan dilakukan pengujian. Pengujian tersebut meliputi pengujian terhadap kualitas citra apakah setelah disisipkan pesan mengalami penurunan kualitas atau tidak dan ketahanan citra stego untuk melihat apakah pesan yang disisipkan masih dapat diekstrak meskipun gambar mengalami beberapa perubahan.

\section{Pembahasan}

Pada format gambar JPEG, masing-masing komponen warna menggunakan transformasi DCT (discrete cosine transform) untuk mentransformasi blokblok gambar 8x8 pixel kedalam 64 masing-masing koefisien DCT (Huang dkk,2012). Koefisien-koefisien DCT tersebut adalah $\mathrm{F}(\mathrm{u}, \mathrm{v})$ dari suatu blok $8 \times 8$ dari citra pixel $f(x, y)$ dinyatakan pada Persamaan (1):

$\left[F(u, v)=\frac{1}{4} C(u) C(v)\left[\sum_{x=0}^{7} \sum_{y=0}^{7} f(x, y) \cos \frac{(2 x+1) u \pi}{16} \cos \frac{(2 y+1) v \pi}{16}\right]\right]$

Pada persamaan $1 \mathrm{~F}(\mathrm{u}, . \mathrm{v})$ berbentuk matriks 2dimensi 8x8 dengan keterangan:

$u, v, x, y=0,1,2, \ldots, 7$

$x, y$ adalah koordinat spatial dari domain asal.

$u, v$ adalah koordinat frekuensi pada domain transformasi atau koefisien-koefisien DCT.

$\mathrm{C}(\mathrm{u}), \mathrm{C}(\mathrm{v})=1 / \sqrt{ } 2$ Untuk $\mathrm{u}, \mathrm{v}=0$

$\mathrm{C}(\mathrm{u}), \mathrm{C}(\mathrm{v})=1$, untuk nilai lainya.

Selanjutnya adalah kuantisasi, proses kuantisasi diterapkan pada keluaran proses DCT. Kuantisasi dilakukan dengan cara membagi keluaran proses DCT dengan suatu nilai yang ditetapkan dalam matriks kuantisasi (Westfeld, 2001). Proses kuantisasi dilakukan dengan Persamaan (2) :

$$
F_{Q}(u, v)=\operatorname{Round}\left(\frac{F[u, v]}{q[u, v]}\right)
$$

\section{Dimana:}

$(\mathrm{q}[\mathrm{u}, \mathrm{v}])=$ tabel kuantisasi

Gambar 1 merupakan nilai kuantisasi komponen luminance dan chrominance standar JPEG.

\begin{tabular}{|rrrrrrrr}
\hline 16 & 11 & 10 & 16 & 24 & 40 & 51 & 61 \\
12 & 12 & 14 & 19 & 26 & 58 & 60 & 55 \\
14 & 13 & 16 & 24 & 40 & 57 & 69 & 56 \\
14 & 17 & 22 & 29 & 51 & 87 & 80 & 62 \\
18 & 22 & 37 & 56 & 68 & 109 & 103 & 77 \\
24 & 35 & 55 & 64 & 81 & 104 & 113 & 92 \\
49 & 64 & 78 & 87 & 103 & 121 & 120 & 101 \\
72 & 92 & 95 & 98 & 112 & 100 & 103 & 99
\end{tabular} \mid \begin{tabular}{rrrrrrrrr|}
17 & 18 & 24 & 47 & 99 & 99 & 99 & 99 \\
18 & 21 & 26 & 66 & 99 & 99 & 99 & 99 \\
24 & 26 & 56 & 99 & 99 & 99 & 99 & 99 \\
47 & 66 & 99 & 99 & 99 & 99 & 99 & 99 \\
99 & 99 & 99 & 99 & 99 & 99 & 99 & 99 \\
99 & 99 & 99 & 99 & 99 & 99 & 99 & 99 \\
99 & 99 & 99 & 99 & 99 & 99 & 99 & 99 \\
99 & 99 & 99 & 99 & 99 & 99 & 99 & 99 \\
\hline
\end{tabular}

Gambar 1. Kuantisasi luminance dan chrominance

LSB dari koefisien DCT yang terkuantisasi digunakan sebagai bit-bit redundant untuk menyisipkan pesan rahasia (Walia dkk, 2010). Pada tahap ini, koefisien DC dari tiap blok disatukan untuk memasuki tahap entropy coding, teknik DPCM (differential pulse code modulation) digunakan karena nilai-nilai koefisien DC antar blok tidak berbeda jauh (Morkel dkk, 2005). Gambar 2 menjelaskan proses DPCM yang diterapkan pada koefisien DC. 


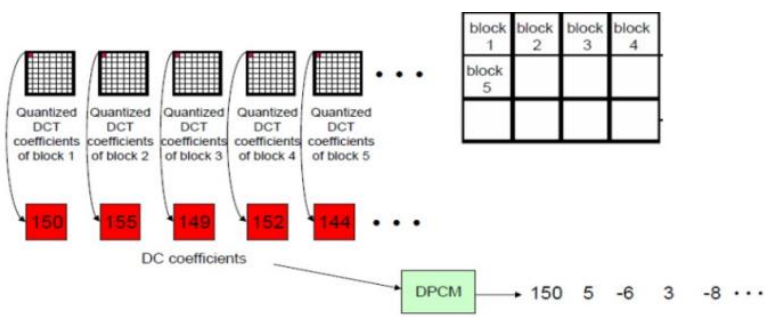

Gambar 2. Differential Pulse Code modulation

\section{A. Entropy Coding pada Koefisien DC}

Koefisien DC yang sudah melalui tahap DPCM kemudian dikompresi menggunakan metode huffman, tetapi sebelumnya deretan angka tersebut akan dirubah bentuknya menjadi pasangan-pasangan (size,amplitude) dimana size menyatakan jumlah bit yang diperlukan untuk merepresentasikan jumlah angka DPCM dan amplitude menyatakan angka tersebut dalam bit (Reddy dan Reddy, 2011). Berikut Tabel 1 yang menyatakan hubungan antara size dan amplitude-nya:

Tabel 1 Hubungan Nilai size dan amplitude-nya

\begin{tabular}{|c|c|c|}
\hline Size & Amplitude Number & Number \\
\hline 1 & 0,1 & $-1,1$ \\
\hline 2 & $00,01,10,11$ & $-3-2,2,3$ \\
\hline 3 & $000, \ldots, 011,100, \ldots, 111$ & $-7, \ldots,-4,4, \ldots, 7$ \\
\hline 4 & $0000, \ldots, 0111,1000, \ldots, 1111$ & $-15, \ldots,-8,8, \ldots, 15$ \\
\hline$\ldots$. & $\ldots$. & $\ldots$ \\
\hline 10 & $0000000000, \ldots, 0111111111,1000000000, \ldots, 1111111111$ & $-1023, \ldots, 512,512, \ldots, 1023$ \\
\hline
\end{tabular}

Pada Gambar 3 merupakan contoh proses huffman pada koefisien DC.

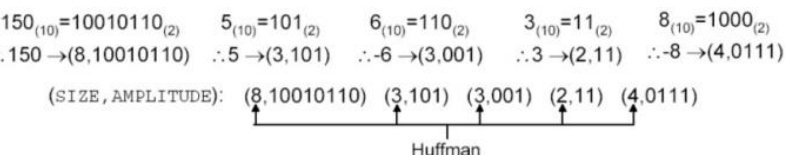

Gambar 3. Proses entropy encoding pada koefisien DC

\section{B. Zig-zag Scanning}

Pada proses zig-zag scanning ini koefisien DCT terkuantisasi yang bernilai nol cenderung terbaca secara berurutan. Gambar 4 merupakan contoh proses zig-zag scan.

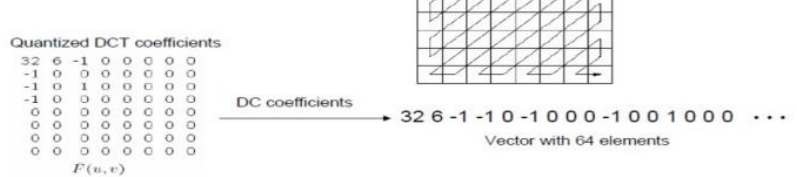

Gambar 4. Proses zig-zag scan

\section{Run Length Code}

RLC (Run Length Code) yaitu proses serangkaian simbol yang berurutan dikodekan menjadi suatu kode yang terdiri dari simbol tersebut dan jumlah pengulanganya. RLC mempunyai dua simbol yaitu:
Symbol 1

(RUNLENGTH, SIZE) (AMPLITUDE)

D. Entropy Coding pada Koefisien AC

AC yang sudah melalui tahap RLC juga dikompresi menggunakan kompresi huffman, pasangan-pasangan sebelumnya diubah lagi menjadi pasangan-pasangan (runlength, size, amplitude). Dalam hal ini yang mengalami kompresi huffman hanya runlength dan sizenya seperti pada koefisien DC. Lebih lanjut dijelaskan dalam Gambar 5 (Morkel dkk, 2005)

$$
\begin{aligned}
& \text { (RUNLENGTH, VALUE) } \rightarrow(\underbrace{\text { RUNLENGTH, SIZE }}_{\text {Huffman }}, \text { AMPLITUDE } \\
& \begin{array}{lllll}
(0,6) & (0,-1) \quad(0,-1) & (1,-1) \quad(3,-1) \quad(2,1) \quad(0,0)
\end{array} \\
& \rightarrow(0,3,110)(\underbrace{0,1}, 0)(\underbrace{0,1}_{\text {Huffman }}, 0)(\underbrace{1,1,0}_{\Psi})(\underbrace{3,1,0})(2,1,1)(\underbrace{0,0})
\end{aligned}
$$

Gambar 5. Proses Entropy Encoding pada koefisien AC

\section{E. Steganografi pada domain DCT}

Proses penyisipan pesan dalam citra dapat dilihat dalam Gambar 6

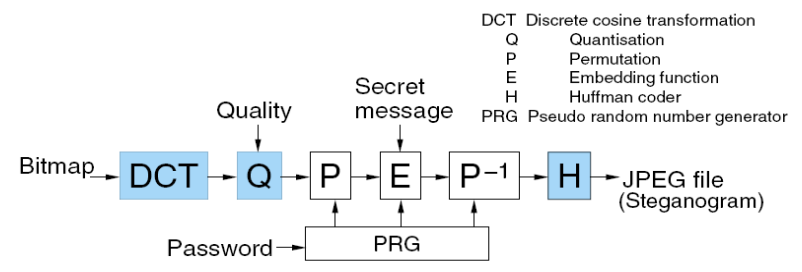

Gambar 6. Proses penyisipan pesan .(Westfeld, 2001)

Dalam proses embedding pesan dalam citra ini pertama-tama dimasukkan (input) file citra. Setelah itu masukkan password atau shared secret sebagai kunci steganografi. Setelah itu ambil pixel dari citra tersebut, kemudian lakukan perhitungan DCT sesuai dengan Persamaan (1) untuk memperoleh koefisien DCT atau domain frekuensinya serta hasil tabel kuantisasinya. Inisialisasi PRNG dengan password yang telah dimasukkan. Setelah itu dilakukan permutasi pada koefisien DCT, lalu dilakukan proses embedding bit data pesan ke dalam koefisien DCT yang telah dipermutasikan. Setelah proses embedding selesai, lakukan invers permutasi terhadap koefisien DCT yang telah disisipkan pesan. Sehingga didapatkan hasil berupa stego image. Selanjutnya dilakukan huffman coding untuk mengkompresi citra sehingga output citra atau stego image merupakan citra dengan format JPEG (*.jpg).

\section{F. Kapasitas Pesan pada steganografi dct}

Perhitungan kapasitas pesan yang dapat disisipkan pada steganografi F5 dilakukan dengan menghitung nilai total koefisien DCT dikurangi dengan koefisien DC, koefisien DCT bernilai nol, serta koefisien DCT bernilai nol hasil proses shrinked. Shrinked terjadi ketika dalam 
proses pengurangan atau penambahan koefisien DCT dengan data pesan, nilai koefisien DCT menjadi nol, proses Shrinked terjadi akan terjadi tergantung dari pesan yang akan disisipkan, sehingga dalam hal ini kapasitas pesan yang dihitung adalah perkiraan kapasitasnya. Formula untuk menghitung kapasitas pesan pada steganografi kawasn det menurut (Sajedi dan Zamjad, 2012) yaitu:

Kapasitas=\#DCT (total) $^{-} \# \mathrm{DCT}_{(-1)^{-}}-\# \mathrm{DCT}_{(1)}-\mathrm{DCT}_{(0)}-\# \mathrm{DCT}_{(\mathrm{dc})}$

Dimana \#DCT(total) $=$ Jumlah total koefisien det

\#DCT(-1) =Jumlah koefisien det bernilai -1

\#DCT(1) =Jumlah koefisien det bernilai 1

\#DCT $(0)=$ Jumlah koefisien dct bernilai 0

\#DCT $(\mathrm{dc})=$ Jumlah koefisien det bernilai dc

\section{G. Entropi Citra}

Entropi citra merupakan salah satu fitur yang dapat dihitung pada matrik GLCM (Gray Level Co-occurrence matrix). Matrix GLCM dihitung dari nilai pixel yang berpasangan dan memiliki nilai intensitas tertentu. Misalkan $d$ adalah jarak antara dua pixel yaitu (x1,y1) dan $(\mathrm{x} 2, \mathrm{y} 2)$ dan $\Theta$ tetha didefinisikan sebagai sudut antara keduanya, maka matrix GLCM merupakan distribusi spasial dari $\mathrm{P}_{\mathrm{d} \Theta}(\mathrm{i}, \mathrm{j})$. Fitur Entropi sendiri merupakan salah satu fitur yang digunakan untuk mengukur kompleksitas atau keacakan suatu citra. Nilai entropi akan bernilai tinggi ketika citra tidak seragam, sebaliknya akan bernilai rendah ketika kompleksitas citra semakin seragam (Sajedi dan Jamzad, 2012).

\section{H. Pengujian Kualitas Fidelity (Stego Image)}

Untuk menentukan PSNR, terlebih dahulu harus ditentukan nilai MSE (Mean Square Error). MSE adalah nilai error kuadrat rata-rata antara citra cover dengan stego image, secara matematis dapat dirumuskan seperti pada Persamaan (3)

MSE

$\frac{1}{M A N} \sum_{Y=1}^{M} \sum_{X=1}^{M}\left[I(x, y)-I^{y}(x, y)\right]^{2}$.

Dimana :

MSE = Nilai Mean Square Error citra steganografi

$\mathrm{M}=$ Panjang citra stego (dalam pixel)

$\mathrm{N}=$ Lebar citra stego (dalam pixel)

$\mathrm{I}(\mathrm{x}, \mathrm{y})=$ nilai piksel dari citra cover

$I^{\prime}(\mathrm{x}, \mathrm{y})=$ nilai piksel pada citra stego

Setelah diperoleh nilai MSE maka nilai PSNR dapat dihitung dari kuadrat nilai maksimum dibagi dengan MSE. Secara matematis, nilai PSNR dirumuskan Persamaan (4) :

PSNR $=10 \log _{10}\left(\frac{\text { MAXi }^{2}}{\text { MSE }}\right)$

Dimana:

MSE = nilai MSE .

MAXi= nilai maksimum dari pixel citra yang digunakan Semakin rendah Nilai MSE maka akan semakin baik, dan semakin besar nilai PSNR maka semakin baik kualitas citra steganografi. Nilai PSNR yang wajar pada perbandingan dua berkas citra adalah 30-50 dB (Fridrich, 2001).

\section{Hasil dan Pembahasan}

Berikut adalah hasil perhitungan kapasitas pesan dari algoritma steganografi DCT F5 pada citra dengan dimensi $128 \times 128$ pixel.

1. Hubungan antara kompleksitas Citra dengan Kapasistas Pesan

Tabel 2 menunjukkan perbandingan kapasitas penyisipan citra asli berdasarkan kompleksitas citra, terlihat kapasitas citra cenderung meningkat seiring meningkatnya kompleksitas citra.

Tabel 2. Hubungan antara kompleksitas Citra dengan kapasitas Pesan

\begin{tabular}{|c|c|c|c|}
\hline No & $\begin{array}{c}\text { Nama Citra } \\
\text { Ori }\end{array}$ & $\begin{array}{c}\text { Nilai } \\
\text { Entropy }\end{array}$ & $\begin{array}{c}\text { Kapasitas } \\
\text { Penyisipan } \\
\text { (bits) }\end{array}$ \\
\hline 1 & Low1.jpg & 5.297 & 6814 \\
\hline 2 & Low2.jpg & 5.359 & 6897 \\
\hline 3 & Low3.jpg & 6.018 & 7816 \\
\hline 4 & Middle1.jpg & 7.450 & 6284 \\
\hline 5 & Middle2.jpg & 7.685 & 6834 \\
\hline 6 & Middle3.jpg & 7.893 & 6463 \\
\hline 7 & High1.jpg & 8.102 & 8380 \\
\hline 8 & High2.jpg & 8.494 & 8252 \\
\hline 9 & High3.jpg & 8.701 & 9264 \\
\hline 10 & Veryhigh1.jpg & 8.809 & 8978 \\
\hline 11 & Veryhigh2.jpg & 8.928 & 11049 \\
\hline 12 & Veryhigh3.jpg & 9.265 & 12047 \\
\hline \multicolumn{2}{|c|}{ Rata-rata } & & $\mathbf{8 2 5 6 . 5}$ \\
\hline
\end{tabular}

2. Hubungan antara kompleksitas citra dengan kualitas citra

Tabel 3 menunjukkan perbandingan nilai PSNR dan MSE pada steganografi DCT, nilai yang didapatkan merupakan perbandingan antara citra asli dengan citra stego.

Tabel 3. Perbandingan Nilai PSNR dan MSE citra asli dengan citra stego

\begin{tabular}{|c|c|c|c|}
\hline No & Nama Citra Asli & PSNR (db) & MSE \\
\hline 1 & Low1.jpg & 32.81 & 104.41 \\
\hline 2 & Low2.jpg & 34.36 & 91.79 \\
\hline 3 & Low3.jpg & 34.78 & 94.83 \\
\hline 4 & Middle1.jpg & 35.31 & 96.58 \\
\hline 5 & Middle2.jpg & 35.40 & 105.79 \\
\hline 6 & Middle3.jpg & 36.12 & 99.72 \\
\hline 7 & High1.jpg & 36.61 & 99.40 \\
\hline 8 & High2.jpg & 37.04 & 99.71 \\
\hline 9 & High3.jpg & 37.37 & 102.94 \\
\hline
\end{tabular}




\begin{tabular}{|l|l|l|l|}
\hline 10 & Veryhigh1.jpg & 38.52 & 82.13 \\
\hline 11 & Veryhigh2.jpg & 38.52 & 82.28 \\
\hline \multicolumn{2}{|l|}{ Rata-Rata } & $\mathbf{3 6 . 0 7}$ & $\mathbf{9 6 . 3 2}$ \\
\hline
\end{tabular}

Berdasarkan kompleksitas citra pada steganografi dct diketahui semakin tinggi kompleksitas citra maka semakin baik nilai PSNR dan MSE yang didapatkan.

3. Hubungan antara Ukuran Pesan dengan Kualitas Citra

Tabel 4 menunjukan data nilai PSNR dan MSE pada citra Middle, terlihat nilai PSNR semakin menurun saat ukuran pesan yang disisipkan semakin tinggi, begitu sebaliknya dengan nilai MSE semakin naik saat ukuran pesan semakin besar.

Tabel 4. Perbandingan kualitas citra berdasarkan ukuran pesan

\begin{tabular}{|c|c|c|c|c|}
\hline No & $\begin{array}{c}\text { Nama Citra } \\
\text { Asli }\end{array}$ & $\begin{array}{c}\text { Ukuran } \\
\text { Pesan(bytes) }\end{array}$ & $\begin{array}{l}\text { PSNR } \\
\text { (db) }\end{array}$ & MSE \\
\hline 1 & Middle1.jpg & 2 & 42.846 & 30.383 \\
\hline 2 & Middle2.jpg & 4 & 42.840 & 30.430 \\
\hline 3 & Middle3.jpg & 6 & 42.827 & 30.520 \\
\hline 4 & Middle4.jpg & 8 & 42.809 & 30.647 \\
\hline 5 & Middle5.jpg & 10 & 42.805 & 30.671 \\
\hline 6 & Middle6.jpg & 12 & 42.784 & 30.819 \\
\hline 7 & Middle7.jpg & 14 & 42.761 & 30.988 \\
\hline 8 & Middle8.jpg & 16 & 42.745 & 31.100 \\
\hline 9 & Middle9.jpg & 18 & 42.748 & 31.076 \\
\hline 10 & Middle10.jpg & 20 & 42.743 & 31.115 \\
\hline \multicolumn{3}{|c|}{ Rata-Rata } & 42.79 & 30.77 \\
\hline
\end{tabular}

\section{Uji Ketahanan}

Berikut adalah hasil pengujian berdasarkan ketahanan citra pada proses steganografi DCT pada 10 citra digital berukuran 128 x 128 piksel dengan format jpg.

\section{Efek Rotasi}

Pada Tabel 5 merupakan data hasil proses ektraksi pesan pada steganografi DCT setelah pemberian efek rotasi vertikal. Dari hasil yang didapatkan tidak ada satupun file pesan yang mampu dibaca kembali.

Tabel 5. Hasil Ektraksi DCT setelah efek rotasi

\begin{tabular}{|c|c|c|}
\hline No & Nama Citra Asli & $\begin{array}{c}\text { Hasil ektraksi } \\
\text { (bit) }\end{array}$ \\
\hline 1 & Low1stegoRotation.jpg & Null \\
\hline 2 & Low2stegoRotation.jpg & Null \\
\hline 3 & Low3stegoRotation.jpg & Null \\
\hline 4 & Middle1stegoRotation.jpg & Null \\
\hline 5 & Middle2stegoRotation.jpg & Null \\
\hline 6 & Middle3stegoRotation.jpg & Null \\
\hline 7 & High1stegoRotation.jpg & Null \\
\hline 8 & High2stegoRotation.jpg & Null \\
\hline 9 & Veryhigh1stegoRotation.jpg & Null \\
\hline 10 & Veryhigh2stegoRotation.jpg & Null \\
\hline
\end{tabular}

\section{b. Efek Penskalaan}

Tabel 6 merupakan data hasil proses ektraksi pesan pada steganografi DCT setelah pemberian efek penskalaan menjadi 150 pixel pada sisi panjang dan sisi lebar . Dari hasil yang didapatkan tidak ada satupun file pesan yang mampu dibaca kembali.

Tabel 6. Hasil Ektraksi DCT setelah efek penskalaan

\begin{tabular}{|c|c|c|}
\hline No & Nama Citra Asli & $\begin{array}{c}\text { Hasil } \\
\text { ektraksi(bit) }\end{array}$ \\
\hline 1 & Low1stegostegoScalling.jpg & Null \\
\hline 2 & Low2stegScalling.jpg & Null \\
\hline 3 & Low3stegoScalling.jpg & Null \\
\hline 4 & Middle1stegScalling.jpg & Null \\
\hline 5 & Middle2stegoScalling.jpg & Null \\
\hline 6 & Middle3stegoScalling.jpg & Null \\
\hline 7 & High1stegoScalling.jpg & Null \\
\hline 8 & High2stegoScalling.jpg & Null \\
\hline 9 & Veryhigh1stegoScalling.jpg & Null \\
\hline 10. & Veryhigh2stegoScalling.jpg & Null \\
\hline
\end{tabular}

\section{Kesimpulan}

a) Steganografi dapat digunakan untuk komunikasi rahasia tanpa mencurigakan karena media penyimpanannya berupa gambar digital yang masih dapat dilihat dengan mata tanpa ada suatu kejanggalan.

b) Kualitas citra stego yang dihasilkan oleh metode steganografi dct tidak jauh berbeda dengan citra aslinya, terlihat dari hasil pengujian rata-rata nilai PSNR yang didapatkan berkisar diatas nilai $30 \mathrm{db}$.

c) Steganografi pada kawasan DCT ini memiliki kelemahan yaitu citra yang telah disisipi pesan tidak tahan terhadap perubahan. Karena setelah dilakukan beberapa perubahan terhadap citra diperoleh hasil bahwa pesan tidak dapat lagi diekstrak. Hal ini disebabkan adanya perubahan warna tiap-tiap piksel citra

\section{DaftarPustaka}

Fridrich, J.,Goljan, M dan Hogea, D., 2002, Steganalysis of JPEG Images Breaking The Algorithm, http://www.ws.binghamton.edu/fridrich/Research/f 5.pdf, diakses 13 Januari 2013.

Huang,F., Huang, J., dan Shi,Y.Q., 2012, New Channel Selection Rule for JPEG Steganography, IEEE Transaction On Information Forensics and Security.,, Vol. 7, No. 4, pp. 1181-1191.

Morkel, T.,Eloff, J.H.P dan Olivier, M.S., 2005, An Overview of Image Steganography, Proceedings of the Fifth Annual Information SecuritySouth Africa Conference, Vol 2, No 3, June, pp.103-112.

Murwantini, S., 2007, Kajian Penyimpanan Data pada Media Citra (Steganografi) menggunakan Metode DCT, Tesis, Program Studi Teknik Elektro UGM,Yogyakarta. 
Patel,H., dan Dave, P., 2012, Steganography Technique Based on DCT Coefficients , International Journal of Engineering Research and Applications (IJERA), Vol. 2, Issue 1, Jan-Feb 2012, pp.713-717.

Reddy,V.L., Subramanyam, A., dan Reddy,C.P., 2011, Steganography + JPEG, International Journal of Computer Graphics., Vol. 2, no. 1, pp. 31-42.

Roy,R., Changder,S. Sarkar, A. dan Debnath,N.C, 2013, Evaluating Image Steganography Techniques: Future Research Challenges, Jurnal of IEEE, pp 309-314.

Sajedi, H dan Jamzad, M., 2012, BSS: Boosted steganography scheme with cover image preprocessing, International Journal of Expert Systems with Applications available at ScienceDirect, pp. 7703-7710.

Walia, E., Jain, P. dan Navdeep., 2010, An Analysis of LSB \& DCT based Steganography, Global Journal of Computer Science and Technology, Vol 10, Issue 1 (Ver 1.0), 4-8.

Westfeld, A., 2001, F5-A Steganographic Algorithm: High capacity despite better steganalysis, Proc. 4th International Workshop on Information Hiding , Springer, vol. 2137, pp. 289-302. 